\title{
Radiometric investigation of different snow covers in Svalbard
}

\author{
Ruggero Casacchia, Francesca Lauta, \\ Rosamaria Salvatori, Anselmo Cagnati, \\ Mauro Valt \& Jon B. Ørbæk
}

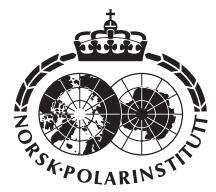

This paper examines the relationship between reflectance and physical characteristics of the snow cover in the Arctic. Field data were acquired for different snow and ice surfaces during a survey carried out at NyÅlesund, Svalbard, in spring 1998. In each measurement session reflectance in the spectral range $350-2500 \mathrm{~nm}$, snow data (including temperature, grain size and shape, density and water content), surface layer morphology, and vertical profile of the snow pack were recorded. A detailed analysis of reflectance based on the physical structure of snow was performed. Field reflectance data were also re-sampled at the spectral intervals of Landsat TM to compare the ability of identifying different snow targets at discrete wavelength intervals. This analysis shows that reliable data on snow structure and thickness are necessary to understand albedo changes of the snow surfaces.

R. Casacchia, F. Lauta \& R. Salvatori, National Research Council, Institute of Atmospheric Pollution, Via Salaria km 29.300 C.P. 10, 00016 Monterotondo Stazione (Roma), Italy; A. Cagnati \& M. Valt, ARPAV CVA, Strada Passo Campolongo 122, 32020 Arabba di Livinallongo (BL), Italy; J. B. Ørbaek, Norwegian Polar Institute, Polar Environmental Centre, N-9296 Tromsø, Norway.

The multitemporal analysis of the snow-covered surfaces in polar regions may provide data useful for monitoring Earth's climate changes. Radiometric data acquired by multispectral satellite images recorded at wavelengths between $400-2500 \mathrm{~nm}$ can support this study, owing to the link between the reflectance and physical characteristics of snow at these wavelengths.

Snow reflectance in the visible part of the electromagnetic spectrum is related to water and ice content, absorbing impurities, and topographic effects, while in the near-infrared wavelengths snow reflectance is more sensitive to grain size (Wiscombe \& Warren 1980; Warren 1982; Dozier 1989). These parameters, together with snow density, are generally an index of the physical conditions of snow, and thus can provide information about the relative ages of various snow- covered surfaces. Reflectance data as derived from Landsat/Thematic Mapper, SPOT and NOAA/ AVHRR have been used to investigate snow/ice surfaces (Hall, Chang \& Siddalingaiah 1988; Hall, Kovalick et al. 1990; Bourdelles \& Fily 1993; Thomas 1993; Winther 1993a). Comparisons of in situ and satellite derived reflectance have also been carried out (Hall, Chang, Foster et al. 1989; Hall, Bindschadler et al. 1990; Winther 1993a, 1993b; Boresjö Bronge \& Bronge 1999). This comparison is important for a correct interpretation of satellite data and for a detailed analysis of snow's spectral behaviour and metamorphic conditions. Furthermore, ground measurements of albedo have been performed on different snow covers and ice surfaces by Gerland et al. (1999), Knap et al. (1999) and Winther et al. (1999).

This paper presents data acquired in a survey 


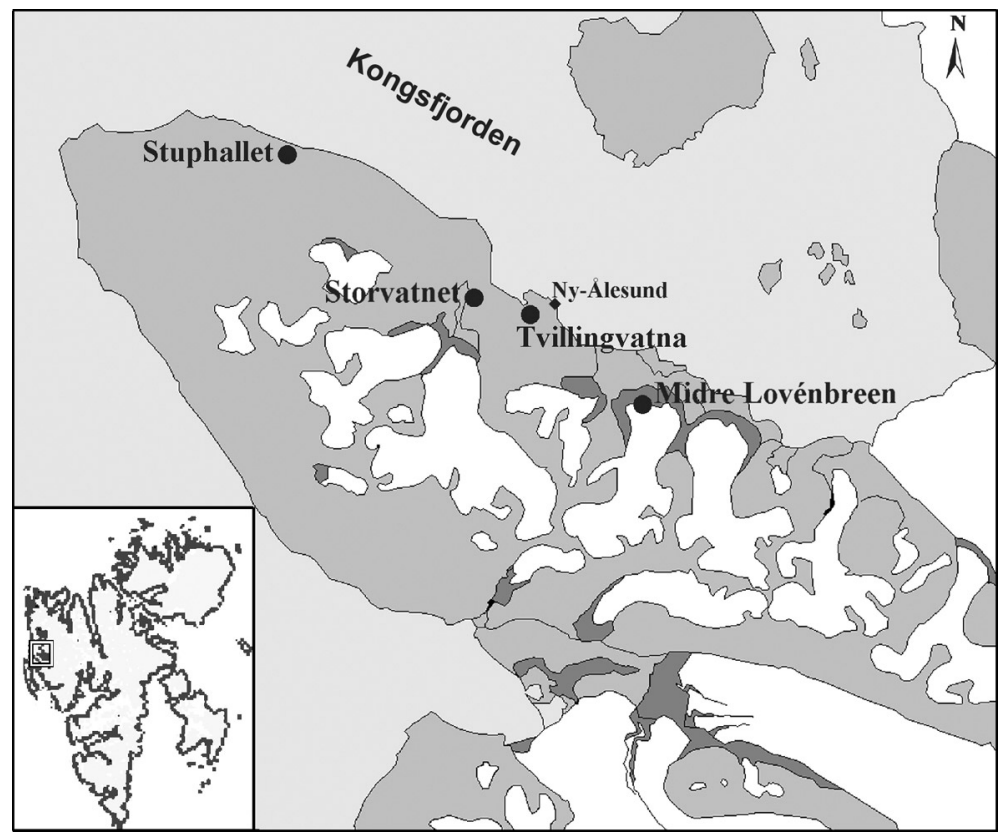

Fig. 1. Map of Brøggerhalvøya (Brøgger Peninsula) showing the location of the investigated sites (see Table 1 for details); Svalbard Archipelago inset. The surface area is about $14 \mathrm{~km}$ by $12 \mathrm{~km}$.

carried out in Svalbard. Field data were analysed to identify quantitative changes in snow cover albedo as a function of snow's physical characteristics. This work is also aimed at providing ground-truth data to support satellite monitoring of snow/ice surfaces.

\section{Spectral characteristics of snow}

Snow is a collection of ice grains and air and often contains organic impurities like dust, soot, pollen and other plant materials. The optical properties of the snowpack in the visible and near-infrared wavelengths depend on grain size distribution, thickness of the snowpack, occurrence of impurities and liquid water content (Wiscombe \& Warren 1980; Warren 1982). The investigation of snow/ice spectral properties usually takes into account the reflectance, defined as the ratio of the radiant energy reflected by a body to that incident upon it. The optical properties of ice can be very different according to ice types. However, in the visible wavelengths, ice is highly transparent, so that its albedo may change according to the amount and pattern of inclusions (Wiscombe \& Warren 1980). In the near-infrared wavelengths ice is more absorptive, so that albedo depends mainly on grain size (Warren \& Wiscombe 1980;
Dozier 1989). Furthermore, snow reflectance is higher in the visible part of the electromagnetic spectrum, decreasing rapidly at longer wavelengths, from about $700 \mathrm{~nm}$. The increase of grain size gives a decrease in reflectance all over the spectral range from visible to shortwave infrared (350- $2500 \mathrm{~nm})$, particularly relevant in the infrared regions (Warren \& Wiscombe 1980; Warren 1982; Warren et al. 1986). The reflectance of both wet and refrozen snow is usually lower than that of dry snow due to the strong absorption coefficient of water and ice, especially at near-infrared and infrared wavelengths.

\section{Field measurements}

Radiometric and snow data were collected between 25 April and 10 May 1998, in four measurement sites on Brøggerhalvøya (Brøgger Peninsula), in the area surrounding the international scientific station of Ny-Ålesund (Fig. 1). This location was chosen because it offered the opportunity of measuring flat, snow/ice surfaces large enough to be sampled on satellite images and far enough from dense human settlement to provide relatively uncontaminated snow spectral signatures. As expected (Ørbæk et al. 1999), the weather conditions in this time period did not 
cause a significant melting of the snow cover, while some snowfall occurred together with storms and clear sky days. All field data were collected during clear sky conditions; air temperatures were always below $0{ }^{\circ} \mathrm{C}$ (Table 1). During the survey sun elevation was between $23^{\circ}$ and $27^{\circ}$. Even though this datum is crucial for reflectance measurements (Winther et al. 1999), in this paper our attention is mainly devoted to the physical structure of snow.

The surveyed snow surfaces usually comprised a mixture of grains of different classes; the snow surface definitions given in this study are based on the most representative grain type. In particular, as mentioned in Table 2, the term "equilibrium forms" is applied to rounded snow grains characterized by almost no growth, because of the low thermal gradient. The analysed snow surfaces were: new snow, equilibrium forms, drifted snow, and basal ice derived from freezing of meltwater.

\section{Snow data}

A conventional survey of snow surfaces was carried out at all measurement sites, including a penetration test and a vertical profile with regard to the top stratum. The penetration test was carried out using a Swiss percussion probe (Rammsonde, cone tip angle $60^{\circ}$, base diameter $40 \mathrm{~mm}$, tube weight $10 \mathrm{~N} / \mathrm{m}$, ram weight $10 \mathrm{~N}$ ). The vertical profile led to the identification of different strata, and the following parameters were reported or estimated for each of them: grain shape and size, hardness (hand test), density and temperature. The water content was investigated, too, using a Snow Fork (Toikka, Finland), though liquid water content of snow was null at all sites. Snow description is based on the international classification of seasonal snow on the ground established by the International Committee for Snow and Ice, International Association of Scientific Hydrology (Colbeck et al. 1990). Surface roughness (furrow distance and depth) was also measured in $\mathrm{mm}$ in accordance with Colbeck et al. (1990). The main physical characteristics of the surveyed snow surfaces are shown in Tables 3 and 4.

\section{Spectroradiometric measurements}

Snow and ice reflectance was acquired by the field spectroradiometer Fieldspec FR (Analytical Spectral Devices Inc., Boulder, CO), covering the wavelength range $350-2500 \mathrm{~nm}$, and calculated

Table 1. Characteristics of the investigated sites.

\begin{tabular}{|c|c|c|c|c|c|c|c|c|}
\hline Surface type & Symbol & Site & $\begin{array}{l}\text { Latitude / } \\
\text { longitude }\end{array}$ & Day & Time & $\begin{array}{c}\text { Average } \\
\text { snow thick- } \\
\text { ness }(\mathrm{mm})\end{array}$ & $\begin{array}{l}\text { Air T } \\
\left({ }^{\circ} \mathrm{C}\right)\end{array}$ & $\begin{array}{l}\text { Sun } \\
\text { elev. }\end{array}$ \\
\hline New snow & $\mathrm{N}$ & Storvatnet & $\begin{array}{l}78^{\circ} 55^{\prime} 28^{\prime \prime} \mathrm{N} \\
11^{\circ} 50^{\prime} 11^{\prime \prime} \mathrm{E}\end{array}$ & 04 May & $13: 30$ & $200(+760)$ & -2.9 & $27^{\circ}$ \\
\hline Equilibrium forms & $\mathrm{E}$ & Storvatnet & $\begin{array}{l}78^{\circ} 55 \text { '28'” N } \\
11^{\circ} 50^{\prime} 11^{\prime \prime} \mathrm{E}\end{array}$ & 27 April & $13: 30$ & 600 & -9.6 & $24^{\circ}$ \\
\hline $\begin{array}{c}\text { Equilibrium forms on } \\
\text { basal ice }(40 \mathrm{~mm})\end{array}$ & $\mathrm{E} 4$ & Tvillingvatna & $\begin{array}{l}78^{\circ} 55^{\prime} 16^{\prime \prime} \mathrm{N} \\
11^{\circ} 55^{\prime} 37^{\prime \prime} \mathrm{E}\end{array}$ & 28 April & $15: 10$ & 40 & -5.7 & $24^{\circ}$ \\
\hline $\begin{array}{c}\text { Equilibrium forms on } \\
\text { basal ice }(10 \mathrm{~mm})\end{array}$ & $\mathrm{E} 1$ & Tvillingvatna & $\begin{array}{l}78^{\circ} 55^{\prime} 16^{\prime \prime} \mathrm{N} \\
11^{\circ} 55^{\prime} 37^{\prime \prime} \mathrm{E}\end{array}$ & 28 April & $15: 00$ & 10 & -5.7 & $24^{\circ}$ \\
\hline Smooth drifted snow & SD & Storvatnet & $\begin{array}{l}78^{\circ} 55^{\prime} 28^{\prime \prime} \mathrm{N} \\
11^{\circ} 50^{\prime} 11^{\prime \prime} \mathrm{E}\end{array}$ & 01 May & $14: 00$ & 760 & -4.3 & $26^{\circ}$ \\
\hline $\begin{array}{l}\text { Drifted snow } \\
\text { (barchans) }\end{array}$ & $\mathrm{DB}$ & Storvatnet & $\begin{array}{l}78^{\circ} 55^{\prime} 28^{\prime \prime} \mathrm{N} \\
11^{\circ} 50^{\prime} 11^{\prime \prime} \mathrm{E}\end{array}$ & 01 May & $13: 15$ & 760 & -4.3 & $26^{\circ}$ \\
\hline $\begin{array}{l}\text { Drifted snow } \\
\text { (ripples) }\end{array}$ & DR & Storvatnet & $\begin{array}{l}78^{\circ} 55^{\prime} 28^{\prime \prime} \mathrm{N} \\
11^{\circ} 50^{\prime} 11^{\prime \prime} \mathrm{E}\end{array}$ & 01 May & $12: 00$ & 760 & -4.3 & $26^{\circ}$ \\
\hline Drifted snow & $\mathrm{DE}$ & Midre Lovénbreen & $\begin{array}{l}78^{\circ} 54^{\prime} 01^{\prime \prime} \mathrm{N} \\
12^{\circ} 02^{\prime} 56^{\prime \prime} \mathrm{E}\end{array}$ & 05 May & $16: 00$ & $>800$ & -6.3 & $24^{\circ}$ \\
\hline Melt-freeze crust & $\mathrm{C}$ & Stuphallet & $\begin{array}{l}78^{\circ} 57^{\prime} 58^{\prime \prime} \mathrm{N} \\
11^{\circ} 37^{\prime} 52^{\prime \prime} \mathrm{E}\end{array}$ & 04 May & $12: 00$ & 200 & -3 & $26^{\circ}$ \\
\hline Basal ice & I & Tvillingvatna & $\begin{array}{l}78^{\circ} 55^{\prime} 16^{\prime \prime} \mathrm{N} \\
11^{\circ} 55^{\prime} 37^{\prime \prime} \mathrm{E}\end{array}$ & 28 April & $15: 30$ & - & -5.7 & $23^{\circ}$ \\
\hline
\end{tabular}




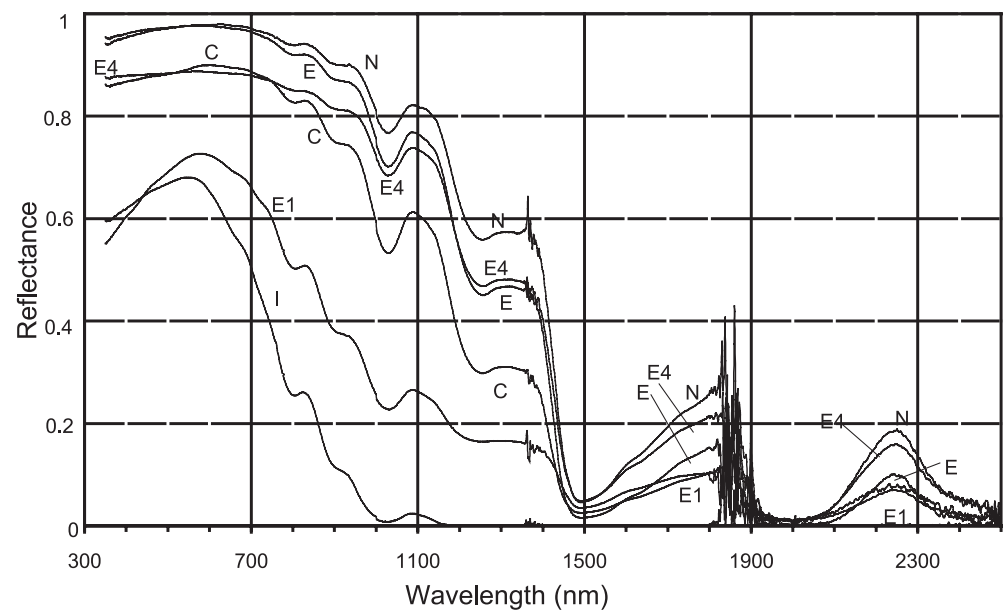

Fig. 2. Reflectance curves of new snow $(\mathrm{N})$, equilibrium forms (E), equilibrium forms $(40 \mathrm{~mm})$ on basal ice (E4), equilibrium forms $(10 \mathrm{~mm})$ on basal ice (E1), bare basal ice (I) and melt-freeze crust (C). as the ratio of incident solar radiation reflected from the snow target and the incident radiation reflected from a white reference Spectralon (about $30 \mathrm{~cm} \times 30 \mathrm{~cm}$ ), known as a Lambertian reflector. This ratio gives the reflectance factor, while the absolute reflectance is obtained by multiplying this reflectance factor with the reflectance spectrum of the panel. Used in the field under harsh environments, the panel requires proper maintenance and calibration for correct calculation of the reflectance data (especially concerning organic impurities affecting the shorter wavelengths).

The Spectralon was re-calibrated at the Norwegian Polar Institute's (NPI) Optical Calibration Laboratory in Ny-Ålesund during the campaign by intercomparison with a primary standard reference Spectralon. The new calibration curve of the panel was thereby obtained, allowing absolute reflectance to be calculated with an error of $2 \%$; this value is derived from the standard deviation of the spectral response of our spectralon (in the entire $350-2500 \mathrm{~nm}$ wavelength range)

Table 2. Definition of snow-related terms used in this paper.

\begin{tabular}{ll}
\hline $\begin{array}{l}\text { New snow } \\
\text { Equilibrium } \\
\text { forms }\end{array}$ & $\begin{array}{l}\text { Snow deposited within 24 hours } \\
\text { Rounded crystals, shaped by a slow growth }\end{array}$ \\
$\begin{array}{l}\text { Drifted snow } \\
\text { Dry snow }\end{array}$ & $\begin{array}{l}\text { Snow deposited or altered by the wind } \\
\text { Deposited snow that has not been subject } \\
\text { to melting or to infiltration of liquid water }\end{array}$ \\
$\begin{array}{c}\text { Melt-freeze } \\
\text { crust }\end{array}$ & $\begin{array}{l}\text { Hard and generally thin layer formed } \\
\text { by recognizable melt-freeze polycrystals } \\
\text { Basal ice }\end{array}$ \\
$\begin{array}{l}\text { Ice occurring at the base of the snow } \\
\text { cover formed from freezing of meltwater }\end{array}$ \\
\hline
\end{tabular}

computed with respect to the NPI's standard reference.

Other sources of errors or noise in field spectroradiometric data may have included incorrect viewing geometry in data acquisition, random noise produced by the electronic components of the instrument, atmospheric water vapour absorption band, and the low atmospheric irradiance at wavelengths of $1400 \mathrm{~nm}$ and beyond $1700 \mathrm{~nm}$, giving a low signal to noise ratio $(\mathrm{S} / \mathrm{N})$. A correct orientation of the spectroradiometer over the panel and the surface is necessary for snow targets, particularly in the visible wavelengths up to $900 \mathrm{~nm}$, to avoid reflectance values that exceed $100 \%$ and reflectance curves that have an anomalous pattern. The $\mathrm{S} / \mathrm{N}$ ratio can be increased by increasing the number of measurements for every radiometric acquisition.

During data acquisition particular attention was devoted to snow surface roughness variability (Table 4). The different pattern and size of surface furrows may cause the spectral response to vary, due both to shadowing effects and to backscattering. To identify all the snow targets to sample, a detailed observation of all the surface variations at each location was carried out before every measurement session. Grain size and shape were detected for each target. Snow observations were performed on the same target immediately after spectral measurements.

Measurements were acquired $500 \mathrm{~mm}$ above the target, with a field of view of $25^{\circ}$, thus covering ground areas of $230 \mathrm{~mm} \times 230 \mathrm{~mm}$. Special care was taken to ensure that the radiometer was nadir viewing over the surveyed surfaces. The 
Fig. 3. Reflectance curves of new snow $(\mathrm{N})$ and drifted snows (SD, DB, DR and DE).

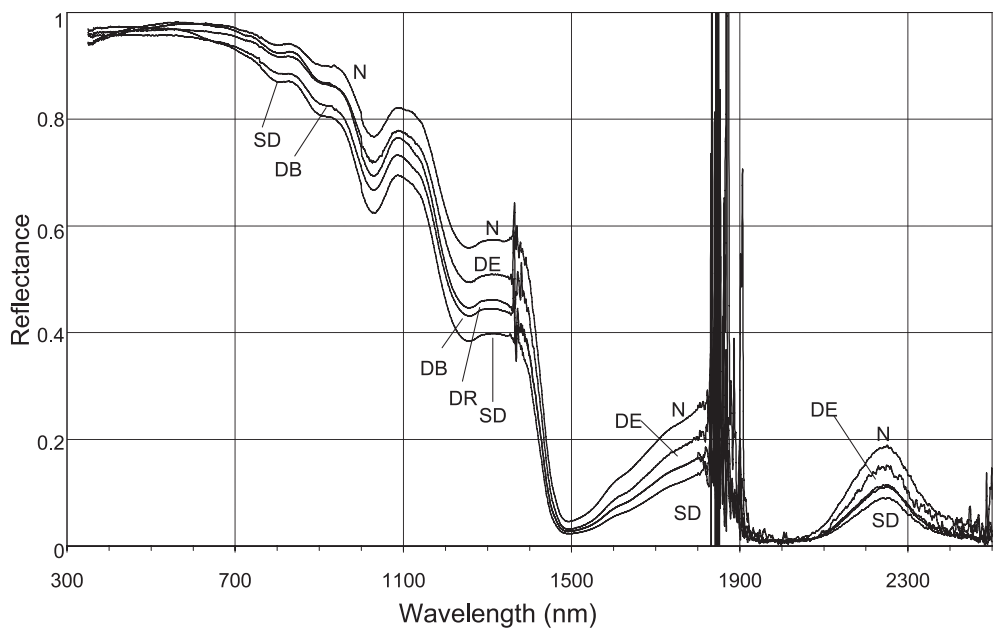

Fieldspec spectroradiometer allows the improvement of the $\mathrm{S} / \mathrm{N}$ ratio of each spectral curve by selecting a specific number of samples to be averaged to obtain the final spectral curve. According to the spectrometer's manufacturer, a sample average from 10 to 150 is sufficient; a larger number of samples would require a longer acquisition time, and stable sky conditions. Because of the weather during our survey, a spectrum averaging of 50 samples was chosen, after having checked that reflectance acquired with a higher number of acquisition gave the same results.
Twenty to thirty spectral curves were acquired for every target in order to have a statistically meaningful sample of each target; the number of acquisitions is a user decision, depending on how stable the signal to be recorded. Increasing the number of spectral curves for each target also contributes to the reduction of random errors, resulting in a better spectral characterization of the target itself. The curves discussed below are absolute reflectances computed as mean values of all the acquisitions collected for each target.

Table 3. Physical characteristics of the investigated targets. Symbols used in Figs. 2, 3 and 4: L = Layer thickness (mm); $\rho=$ density $(\mathrm{kg} / \mathrm{m} 3) ; \mathrm{R}=$ hardness; $\mathrm{T}=$ snow temperature $\left({ }^{\circ} \mathrm{C}\right)$.

\begin{tabular}{|c|c|c|c|c|c|c|}
\hline Surface type & Symbol & $\mathrm{L}$ & $\rho$ & $\mathrm{R}$ & $\mathrm{T}$ & Snow crystals \\
\hline New snow & $\mathrm{N}$ & 30 & 55 & very low & -0.7 & $\begin{array}{l}\text { partly decomposed particles }(1.5 \mathrm{~mm}) \\
\text { and stellar dendrites }(3 \mathrm{~mm})\end{array}$ \\
\hline Equilibrium forms & $\mathrm{E}$ & 80 & 145 & very low & -11.9 & $\begin{array}{l}\text { small rounded particles }(0.3-0.5 \mathrm{~mm}) \text {, } \\
\text { highly broken particles }(0.5 \mathrm{~mm}) \\
\text { rare surface hoar crystals }(0.5 \mathrm{~mm})\end{array}$ \\
\hline $\begin{array}{l}\text { Equilibrium forms } \\
(40 \mathrm{~mm}) \text { on basal ice }\end{array}$ & E4 & 40 & 135 & very low & -6.2 & $\begin{array}{l}10 \mathrm{~mm} \text { : partly decomposed precipitation } \\
\text { particles }(1 \mathrm{~mm}) \text {, stellar dendrites }(2.5 \mathrm{~mm}) \text {, } \\
\text { surface hoar crystals }(0.5 \mathrm{~mm}) ; \\
30 \mathrm{~mm} \text { : small rounded particles }(0.5 \mathrm{~mm}) \text {, } \\
\text { surface hoar crystals }(1 \mathrm{~mm})\end{array}$ \\
\hline $\begin{array}{l}\text { Equilibrium forms } \\
\qquad(10 \mathrm{~mm}) \text { on basal ice }\end{array}$ & E1 & 10 & n.d. & very low & n.d. & $\begin{array}{l}\text { partly decomposed precipitation particles }(1 \mathrm{~mm}) \text {, } \\
\text { surface hoar crystals }(0.5 \mathrm{~mm})\end{array}$ \\
\hline Smooth drifted snow & SD & 110 & 385 & high & -5.8 & small rounded particles $(0.3 \mathrm{~mm})$ \\
\hline Drifted snow (barchans) & s) $\mathrm{DB}$ & 110 & 385 & high & -5.8 & small rounded particles $(0.3 \mathrm{~mm})$ \\
\hline Drifted snow (ripples) & DR & 110 & 385 & high & -5.8 & small rounded particles $(0.3 \mathrm{~mm})$ \\
\hline Drifted snow & $\mathrm{DE}$ & 20 & 100 & very low & -5.4 & $\begin{array}{l}20 \mathrm{~mm} \text { : partly decomposed particles }(1.5 \mathrm{~mm}) \\
\text { stellar dendrites }(3 \mathrm{~mm}) \text {, surface hoar; } \\
20 \mathrm{~mm} \text { : small rounded particles }(0.4 \mathrm{~mm})\end{array}$ \\
\hline Melt-freeze crust & $\mathrm{C}$ & 30 & n.d. & high & -1.5 & mixed forms $(0.8 \mathrm{~mm})$ and rounded polycrystals $(1.2 \mathrm{~mm})$ \\
\hline Basal ice & I & 150 & n.d. & very high & n.d. & \\
\hline
\end{tabular}



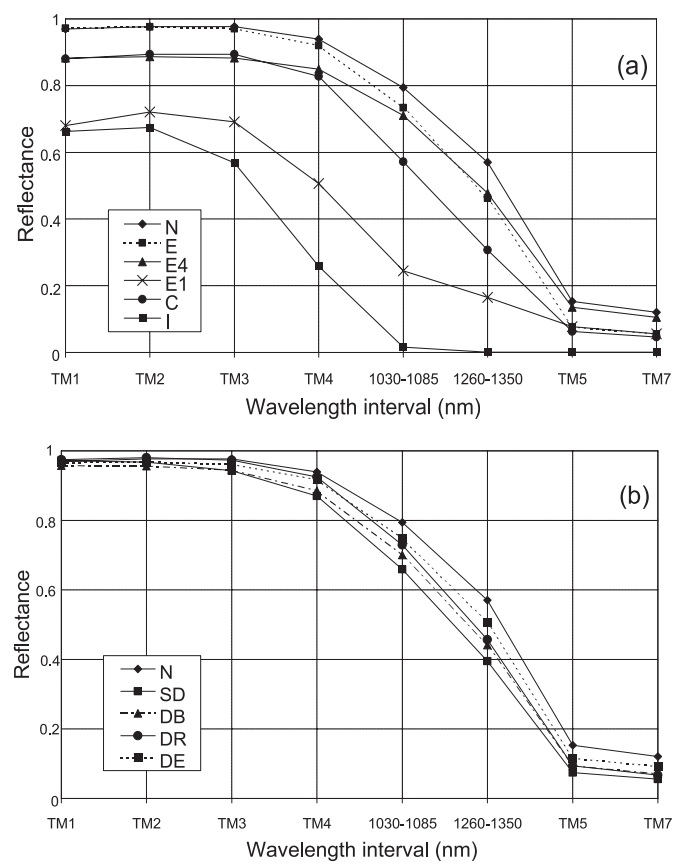

Fig. 4. Reflectance values re-sampled in discrete wavelength intervals: (a) equilibrium forms (E, E4, E1), basal ice (I), melt-freeze crust (C); (b) drifted snows (SD, DB, DR and $\mathrm{DE})$. New snow $(\mathrm{N})$ is shown in both plots.

\section{Analysis of spectra}

At wavelengths between 350 and $2500 \mathrm{~nm}$ the snow physical characteristics that mostly affect reflectance are grain size, presence of absorbing impurities, water content and surface morphologic and geometric characteristics (Wiscombe \& Warren 1980; Warren 1982; Dozier 1989).
Figure 2 presents the spectral albedo of new snow $(\mathrm{N})$, melt-freeze crust $(\mathrm{C})$, equilibrium forms (E), equilibrium forms with thicknesses of $40 \mathrm{~mm}$ (E4) and $10 \mathrm{~mm}$ (E1) on basal ice, and bare basal ice (I); Fig. 3 shows new snow (N) and drifted snow surfaces sampled at Midre Lovénbreen (DE) and three drifted snow surfacessmooth (SD), with surface barchans (DB), with surface ripples (DR) - sampled at Storvatnet. New snow reflectance is shown in both Figs. 2 and 3 , as it is used as a reference to which compare the spectral response of the other snows. Tables 3 and 4 report the main physical characteristics of the surveyed surfaces. The general trends of the reflectance values (Figs. 2, 3) agree with those reported by other authors (Wiscombe \& Warren 1980; Warren 1982; Warren et al. 1986; Hall, Chang \& Siddalingaiah 1988; Dozier 1989; Hall, Chang, Foster et al. 1989; Hall, Bindschadler et al. 1990; Hall, Kovalick et al. 1990; Zibordi et al. 1996; Winther et al. 1998): reflectance is higher in the visible region of the spectrum, and decreases at longer wavelengths. Atmospheric water vapour absorption causes low $\mathrm{S} / \mathrm{N}$ ratio affecting all the measurements at $1400 \mathrm{~nm}$, between $1700-2000 \mathrm{~nm}$ and beyond $2300 \mathrm{~nm}$; two reflectance minima can also be observed at $1500 \mathrm{~nm}$ and $2000 \mathrm{~nm}$. Beyond $1700 \mathrm{~nm}$ the incident radiation is very low; this is a further source of radiometric error affecting infrared data.

The new snow curve $(\mathrm{N})$ pattern shown in Fig. 2 is typical for this surface: its measured albedo is higher between $350-700 \mathrm{~nm}$ (values of $0.94-0.98$ ), and shows lower values at wavelength greater than $700 \mathrm{~nm}$. Its high reflectance is owed to the shape and size of the new snow grains (Table 3), which have not been altered since dep-

Table 4. Surface roughness of the investigated targets.

\begin{tabular}{|c|c|c|c|c|}
\hline Surface type & Symbol & Surface roughness & Furrow distance & Furrow depth \\
\hline New snow & $\mathrm{N}$ & small irregular ripples & $7 \mathrm{~mm}$ & $2 \mathrm{~mm}$ \\
\hline Equilibrium forms & $\mathrm{E}$ & smooth, little ripples & $0.5-1 \mathrm{~mm}$ & $0.1 \mathrm{~mm}$ \\
\hline $\begin{array}{l}\text { Equilibrium forms } \\
(40 \mathrm{~mm}) \text { on basal ice }\end{array}$ & E4 & smooth & & \\
\hline $\begin{array}{l}\text { Equilibrium forms } \\
(10 \mathrm{~mm}) \text { on basal ice }\end{array}$ & E1 & smooth & & \\
\hline Smooth drifted snow & SD & smooth & & \\
\hline Drifted snow (barchans) & DB & snow barchans & $5 \mathrm{~mm}$ & $0.5-1 \mathrm{~mm}$ \\
\hline Drifted snow (ripples) & DR & irregular ripples & $5-10 \mathrm{~mm}$ & $1-1.5 \mathrm{~mm}$ \\
\hline Drifted snow & $\mathrm{DE}$ & irregular furrows & $4 \mathrm{~mm}$ & $0.5-1 \mathrm{~mm}$ \\
\hline Melt-freeze crust & $\mathrm{C}$ & concave furrows & $5 \mathrm{~mm}$ & $1 \mathrm{~mm}$ \\
\hline Basal ice & I & smooth & & \\
\hline
\end{tabular}


osition. The equilibrium forms (E) reflectance curve is close to that of new snow $(\mathrm{N})$ in the visible part of the spectrum (within $3 \%$ up to $900 \mathrm{~nm}$ ). For wavelengths greater than $900 \mathrm{~nm}$, albedo of $\mathrm{E}$ is considerably lower than that of new snow $(\mathrm{N})$, probably due to the presence of surface hoar and to different grain size and shape. The "equilibrium forms" grains are more rounded than new snow grains, giving a reduced reflectance at these wavelengths (Wiscombe \& Warren 1980; Warren 1982; Zibordi et al. 1996). The "equilibrium forms" (40 mm) on ice curve (E4) shows high reflectance $(0.8-0.89)$ up to $900 \mathrm{~nm}$, and is about $10 \%$ lower than new snow $(\mathrm{N})$ and equilibrium forms (E) curves; the comparison between the curves of equilibrium forms $(\mathrm{E})$ and of equilibrium forms on basal ice (E4) reveals that the increased grain size, the presence of surface hoar and of ice below the snow cover determine a lower reflectance of $\mathrm{E} 4$ with respect to E. In the infrared, beyond $1600 \mathrm{~nm}$ the opposite case is observed, as E4 reflectance is higher than reflectance measured on $\mathrm{E}$, because $\mathrm{E} 4$ surface snow grains are less rounded, as revealed by snow field data. The equilibrium forms $(10 \mathrm{~mm})$ on ice (E1) reflectance is considerably lower than previous ones, owing to the presence of ice close to the surface and of surface hoar. This curve pattern is similar to the basal ice curve (I) between $350-1200 \mathrm{~nm}$; reflectance values of the two curves are very close up to $550 \mathrm{~nm}$ and appear more separate as wavelength increases. Between 550 and $600 \mathrm{~nm}$, the E1 curve shows a reflectance maximum of 0.73 , followed by a sharp decrease beyond $600 \mathrm{~nm}$, although it never falls to zero, as basal ice albedo does. We can therefore infer, according to the measurements carried out, that $10 \mathrm{~mm}$ of snow considerably affect ice albedo, mainly in the infrared wavelengths. The basal ice reflectance (I) is lower than any other surface at wavelengths greater than $450 \mathrm{~nm}$. Ice reflectance increases from $350 \mathrm{~nm}$ up to $550 \mathrm{~nm}$, where a maximum of 0.68 occurs, and then rapidly decreases to zero because of the high spectral absorption at $1200 \mathrm{~nm}$. Ice spectral behaviour has been investigated by Wiscombe \& Warren (1980), Warren (1982), Dozier (1989); in particular, the minimum in the ice absorption coefficient curve reported by Dozier (1989) seems to correspond to the reflectance maximum of curve (I) in Fig. 2. According to these reflectance data, the presence of a snow cover on an ice stratum significantly affects its reflectance. At visible and NIR wave-
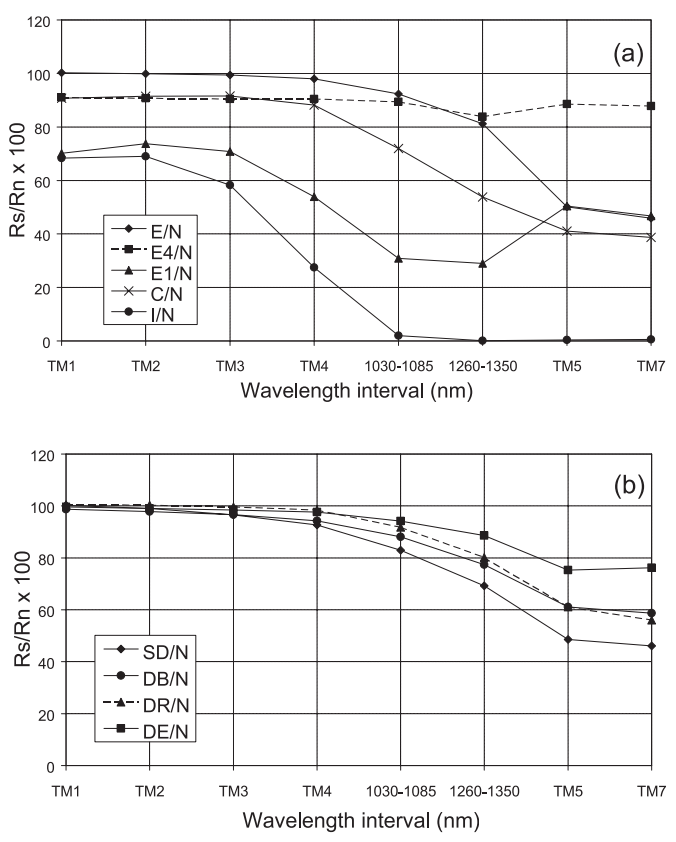

Fig. 5. Reflectance values (Rs) re-sampled in discrete wavelength intervals and normalized with respect to new snow reflectance (Rn): (a) equilibrium forms (E, E4, E1), basal ice (I), melt-freeze crust (C); (b) drifted snows (SD, DB, DR and $\mathrm{DE})$.

lengths up to $1350 \mathrm{~nm}$ there is a wide gap between ice with a snow cover thickness of $40 \mathrm{~mm}$ (E4), ice covered by $10 \mathrm{~mm}$ of snow (E1) and basal ice (I); beyond $1350 \mathrm{~nm}$ the differences are reduced. Moreover, comparing new snow $(\mathrm{N})$, melt-freeze crust (C) and basal ice (I) curves, we observe that increasing metamorphism and age of grains cause a progressive decrease in reflectance at wavelength between 350 and $1400 \mathrm{~nm}$.

The albedo measurements of new snow and of drifted snows measured respectively at Storvatnet (N, SD, DB, DR) and Midre Lovénbreen (DE) are shown in Fig. 3. At Storvatnet drifted snow surfaces have the same physical and granulometric characteristics, but different surface roughness, according to which three kinds of drifted snows have been defined and described in Tables 3 and 4. In the visible part of the spectrum all curves are similar and show reflectance values higher than 0.93; at $700 \mathrm{~nm}$ they appear more distinctive and from 1000 up to $2500 \mathrm{~nm}$ a progressive decrease in reflectance can be noticed, from new snow $(\mathrm{N})$, followed by drifted snow with irregular furrows (DE), and drifted snows characterized, respec- 
tively, by barchans (DB), ripples (DR) and a smooth surface (SD). Due to the occurrence of surface hoar, at infrared wavelengths reflectance of drifted snow (DE) is lower than that of new snow (Fig. 3). The lower albedo measured at Storvatnet ( $\mathrm{SD}, \mathrm{DB}$ and $\mathrm{DR})$ with respect to that acquired at Midre Lovénbreen (DE) is due to the occurrence of smaller and more rounded snow grains. Moreover, the main differences in albedo among the drifted snow surfaces at Storvatnet can be seen at about 1100 and $1300 \mathrm{~nm}$, where probably drifted snows DR and DB surface roughness lead to higher reflectance than that of smooth drifted snow (SD).

\section{Discussion}

The analysis of the reflectance curves (Figs. 2, 3 ) has shown the possibility of identifying different kinds of snow/ice surfaces based on the spectral response between wavelengths of 350 and $2500 \mathrm{~nm}$. The same curves have been analysed in discrete spectral intervals covered by the Landsat 5 Thematic Mapper, with the purpose of comparing field reflectance with satellite-derived data (Fig. 4). In addition, we observe in our data (Figs. $2,3)$ significant reflectance differences even at $1030-1085 \mathrm{~nm}$ and $1260-1350 \mathrm{~nm}$. Satellite data represent an integration of the reflectance recorded over a broad spectral band; field data have to be expressed in the same way to allow a proper comparison. Therefore, in Fig.4 the reflectance values of the surveyed surfaces are shown, averaged over the considered spectral intervals. These data allow the quantitative estimatation of the reflectance of the different snow-covered surfaces in defined spectral intervals, providing useful information for satellite data interpretation. Considering instrument errors, it has been estimated that reflectance variations exceeding $5 \%$ could be great enough to detect significant differences among the surveyed surfaces.

At wavelengths corresponding to TM1 $(450-520 \mathrm{~nm})$, TM2 (520 - $600 \mathrm{~nm})$ and TM3 $(620-690 \mathrm{~nm})$ bands, new snow $(\mathrm{N})$, drifted snows and equilibrium forms (E) have similar and very high albedo ( $>0.94$; Fig. 4a, b). At these wavelengths equilibrium forms on ice (E4) and melt-freeze crust (C) reflect the solar incident radiation with similar intensity. In the same spectral bands all the other surfaces are progressively less reflective, as surface hoar increases. Between
$1030-1086 \mathrm{~nm}$ and 1260 - $1350 \mathrm{~nm}$, E4 reflects up to $17 \%$ more radiation than a melt-freeze crust (C), though its particles are slightly larger and hoar covers the surface. New snow $(\mathrm{N})$, drifted snows (SD, DB, DR and DE) and equilibrium forms (E) begin to be distinguished from TM4 (760 - $900 \mathrm{~nm}$ ) wavelength interval, where new snow can be clearly distinguished from smooth drifted snow (SD) and snow with surface barchans (DB). At 1030 - $1085 \mathrm{~nm}$ the grain and morphologic characteristics of new snow $(\mathrm{N})$ make it more reflective than drifted snows (DB, DR, $\mathrm{DE}$ and SD). Between 1260 and $1350 \mathrm{~nm}$ new snow $(\mathrm{N})$ reflectance is higher than that of drifted snow (DE), which has the same grain size but appears covered by surface hoar. Still at wavelengths longer than $1000 \mathrm{~nm}$, new snow (N) can be distinguished from equilibrium forms (E), characterized by rounded grains and surface hoar (Fig. 4a). Reflectance differences of drifted snows with the same thickness and grain characteristics are due to surface roughness: smooth snow (SD) can be distinguished from $5-10 \mathrm{~mm}$ furrowed snow surfaces (DB and DR) at $1030-1085 \mathrm{~nm}$ and 1260 - $1350 \mathrm{~nm}$ wavelength ranges (Fig. 4b). Between 1260 and $1350 \mathrm{~nm}$ it appears also possible to distinguish drifted snows considering the different grain shape, as for drifted snow (DE) and the surface roughness for drifted snows SD, $\mathrm{DB}, \mathrm{DR}$, while the presence of surface hoar seems to be less decisive. In TM5 (1550 - $1750 \mathrm{~nm})$ and TM7 (2080 - $2350 \mathrm{~nm})$ bands the low albedo of equilibrium forms (E) with respect to the other surfaces is due to the presence of surface hoar. The basal ice reflectance (I) is lower than those of the surveyed snows and is therefore easily distinguished in the first four spectral intervals considered. However, when $10 \mathrm{~mm}$ of snow cover the ice, an appreciable change in albedo is observed (E1), mainly at wavelengths beyond $600 \mathrm{~nm}$; at TM5 and TM7, the E1 curve coincides with that of $E$ because of the effect of backscattering due to the presence of snow, an effect particularly strong at these spectral channels.

To better emphasize mutual reflectance changes, the reflectances of the surveyed surfaces were normalized to new snow and shown in Fig. 5a and b: in these plots higher values signify reflectance similar to that of new snow. The distance between normalized reflectance values at each wavelength interval reveal the possibility of detecting different snow surfaces, even though their original reflectance values were very similar. The infor- 
mation retrieved from this figure is similar to that obtained from Fig. 4, particularly concerning the first four TM spectral channels and the 1030 1085 range. In the $1260-1350 \mathrm{~nm}$, TM5 and TM7 wavelength intervals differences are markedly higher than those in Fig. 4.

\section{Conclusions}

Field spectroradiometric data of different snow/ ice surfaces confirm the necessity of examining thoroughly the relation between snow reflectance and snow metamorphic state. Although ice and snow behaviour is generally well known in the spectral interval $350-2500 \mathrm{~nm}$, a better understanding of snow/ice reflectance under natural conditions would substantially improve the interpretation of their physical features based on reflectance data. Fieldwork also revealed that snow grain size is often larger than that used in the snow spectral models proposed (Wiscombe \& Warren 1980): snow is made up of four to five kinds of grain differing in size and shape, decisively affecting the snow spectral response, particularly in the infrared.

It has also been observed that significant changes in surface reflectance properties are related to the occurrence of hoar and that a detailed characterization of the sub-surface snow (snow layering, metamorphism) is also highly important for data interpretation. Surface roughness, which increases as furrow distance decreases (Table 4), contributes to increasing reflectance particularly at wavelength higher than $1000 \mathrm{~nm}$. This is especially evident in the case of drifted snows where the smoother the surface the lower the reflectance. Moreover, reflectance increases when snow crystals are not rounded (regardless of their size) and surface roughness is relatively high, while reflectance decreases as rounded particles became larger in size and the presence of surface hoar and impurities is higher. However, it is not always possible to identify precisely the feature that mainly determines snow field reflectance, which is the sum of the above-mentioned factors. This has important implications when field spectroradiometric data have to be used to support satellite data interpretation, unless a broad description of snow physical characteristics is required. Based on the data shown in Figs. 4 and 5, better results concern the discrimination between new and drifted snows with respect to melt-freeze crust, bare basal ice and basal ice covered by a thin snow layer. A snow layer $40 \mathrm{~mm}$ thick over basal ice show reflectance values close to those of the melt-freeze crust in the visible and the near-infrared and is close to that of equilibrium forms at wavelengths greater than $1000 \mathrm{~nm}$. Reflectance differences between new snow and drifted snows are difficult to detect, unless the 1030 - 1085 and $1260-1350 \mathrm{~nm}$ wavelength ranges are considered.

The use of a number of spectral channels larger than those presently available on the TM sensor would help in snow and ice monitoring, particularly if the 1030 - 1085 and $1260-1350 \mathrm{~nm}$ wavelength ranges were considered in designing future satellite sensors. And our knowledge of the interaction between snow and solar radiation can be enhanced by improving field data acquisition techniques, devoting more attention to features like surface roughness and grain size assemblages.

It is important both to intensify snow field surveys in different glacial environments and to repeat the same measurements under different climatic, atmospheric and solar conditions. It is also of importance to collect accurate data about snow's physical and textural characteristics along with spectroradiometric data, because a correct interpretation of snow spectral response would be extremely difficult without this information.

Acknowledgements.-This work has been supported by the CNR (National Research Council of Italy) Arctic Strategic Project and by the National Research Programme in Antarctica (Project Remote Sensing, GIS and Hydrography). Special thanks go to Mr. Roberto Sparapani for logistic support during the field survey. The authors also wish to thank Dr. J.-G. Winther and Dr. S. Gerland from the Norwegian Polar Institute (the latter now with the Norwegian Radiation Protection Authority) for their availability to discuss snow reflectance acquisition methods, and Dr. B. Johnsen from the Norwegian Radiation Protection Authority for valuable optical calibration experience.

\section{References}

Boresjö Bronge, L. \& Bronge, C. 1999: Ice and snow-type classification in the Vestfold Hills, East Antarctica, using Landsat-TM and ground radiometer measurements. Int. J. Remote Sens. 20, 225-240.

Bourdelles, B. \& Fily, M. 1993: Snow grain-size determination from Landsat imagery over Terre Adélie, Antarctica. Ann. Glaciol. 17, 86-92.

Colbeck, S., Akitaya, E., Armstrong, R., Gubler, H., Lafeuille, 
J., Lied, K., McClung, D. \& Morris, E. 1990: The international classification for seasonal snow on the ground. International commission on snow and ice report. Wallingford, UK: International Association of Scientific Hydrology.

Dozier, J. 1989: Spectral signature of alpine snow cover from Landsat Thematic Mapper. Remote Sens. Environ. 28, 9-22.

Gerland S., Winther J.-G., Ørbæk J. B., Liston G. E., Øritsland N. A., Blanco, A. \& Ivanov, B. 1999: Physical and optical properties of snow covering Arctic tundra on Svalbard. Hydrol. Process. 13, 2331-2343.

Hall, D. K., Bindschadler, R. A., Foster, J. L., Chang, A. T. C. \& Siddalingaiah, H. 1990: Comparison of in situ and satellite-derived reflectances of Forbindels Glacier, Greenland. Int. J. Remote Sens. 11, 493-504.

Hall, D. K., Chang, A. T. C., Foster, J. L., Benson, C. S. \& Kovalick, W. M. 1989: Comparison of in situ and Landsat derived reflectance of Alaskan glaciers. Remote Sens. Environ. $28,23-31$.

Hall, D. K., Chang, A. T. C. \& Siddalingaiah, H. 1988: Reflectance of glaciers as calculated using Landsat-5 Thematic Mapper data. Remote Sens. Environ. 25, 311-321.

Hall, D. K, Kovalick, W. M. \& Chang, A .T. C. 1990: Satellitederived reflectance of snow-covered surfaces in northern Minnesota. Remote Sens. Environ. 33, 87-96.

Knap, W. H., Reijmer, C. H. \& Oerlemans, J. 1999: Narrowband to broadband conversion of Landsat TM glacier albedoes. Int. J. Remote Sens. 20, 2091-2110.

Ørbæk, J. B., Hisdal V. \& Svaasand L. E. 1999: Radiation climate variability in Svalbard: surface and satellite observations. Polar Res. 18, 127-134.

Thomas, R. H. 1993: Ice sheets. In R. J. Gurney et al. (eds.):
Atlas of satellite observations related to global change. Pp. 385-400. Cambridge: Cambridge University Press.

Warren, S. G. 1982: Optical properties of snow. Rev. Geophys. Space Phys. 20, 67-89.

Warren, S. G., Grenfell, T. C. \& Mullen, P. C. 1986: Optical properties of Antarctic snow. Antarct. J. U. S. 21, 247-248.

Warren, S. G \& Wiscombe, W. J. 1980: A model for the spectral albedo of snow. II: Snow containing atmospheric aerosols. J. Atmos. Sci. 37, 2734-2745.

Winther, J.-G. 1993a: Studies of snow surface characteristics by Landsat TM in Dronning Maud Land, Antarctica. Ann. Glaciol. 17, 27-34.

Winther, J.-G. 1993b: Landsat TM derived and in situ summer reflectance of glaciers in Svalbard. Polar Res. 12, 37-55.

Winther, J.-G., Gerland, S., Ørbæk, J. B., Ivanov, B., Blanco, A. \& Boike, J. 1998: Spectral reflectivity and physical properties of snow and sea ice near Ny-Ålesund, Svalbard. Proceedings of the 4th Ny-Alesund Seminar the Arctic and Global Change. Ravello, Italy, 5-6 March 1998. NySMAC Publ. 7, 113-116. Longyearbyen: Ny-Ålesund Science Managers Committee.

Winther, J.-G., Gerland, S., Ørbæk, J. B., Ivanov, B., Blanco, A. \& Boike, J. 1999: Spectral reflectance of melting snow in a high Arctic watershed on Svalbard: some implications for optical satellite remote sensing studies. Hydrol. Process. 13, 2033-2049.

Wiscombe, W. J. \& Warren, S. G. 1980: A model for the spectral albedo of snow. I: Pure snow. J. Atmos. Sci. 37, 2712-2733.

Zibordi, G., Meloni, G. P. \& Frezzotti, M. 1996: Snow and ice reflectance spectra of the Nansen Ice Sheet surfaces. Cold Reg. Sci. Technol. 24, 147-151. 